\title{
Vertical Externalities in a Tax Setting in a System of Hierarchical Governments
}

\author{
Chao-Lan Wang ${ }^{1}$, Yi-Chung Hsu ${ }^{2}$ \\ ${ }^{1}$ Department of Accounting, National Dong Hwa University, Hualien, Chinese Taipei \\ ${ }^{2}$ Department of Public Finance and Taxation, National Taichung University of Science \& Technology, Taichung, Chinese Taipei \\ Email: hsuyichung@yahoo.com.tw,myhsu@nutc.edu.tw
}

Received February 19, 2013; revised March 19, 2013; accepted April 19, 2013

Copyright (C) 2013 Chao-Lan Wang, Yi-Chung Hsu. This is an open access article distributed under the Creative Commons Attribution License, which permits unrestricted use, distribution, and reproduction in any medium, provided the original work is properly cited.

\begin{abstract}
This paper focuses on the overlap in the tax bases between two levels of government. This overlap leads to vertical fiscal externalities that arise when several different commodities are in the tax base and the tax bases of the two levels of government may not be identical. In the unified government's case, if it is supposed that the marginal utilities of income for the two states are the same, the tax policy in state $i$ not only considers the price elasticity and cross elasticity of each state, but also the shares of expenditure on commodities $x_{1}$ and $x_{2}$ in the different states. When the cross elasticity is zero, the tax rates on the same commodity sold in the different states and the price elasticity should be inversely related. If the cross elasticity of the commodities is zero, the higher the marginal utility of income of state $i$, the lower should be the tax rate set by the unified government in state $i$.
\end{abstract}

Keywords: Vertical Externality; Optimal Tax Rate

\section{Introduction}

A federal structure of government involves at least two levels of government, a higher level as well as a set of lower level jurisdictions. Current federations composed of a national as well as a set of local governments allow both levels of government to exercise certain spending responsibilities, and both levels use taxation as one source of revenue. In a federation, fiscal externalities easily arise and distinctions can be made between tax and expenditure externalities as well as between direct horizontal and indirect horizontal and vertical externalities (Dahlby, 1996 [1]). Within such a structure, the federal government has often been seen as having two fiscal roles: redistribution across the states of the federation and also the internalization of horizontal fiscal externalities. The federal government might achieve such internalization by coordinating the decisions made by the states, leaving the formal decision-making powers to the states, while it matches grants to deal with expenditure spillovers and so on (Keen, 1998 [2]).

The literature on tax competition among governments for mobile tax bases has drawn attention to one of the most widely debated public finance issues ${ }^{1}$. Hoyt (2001) [5] points out that horizontal fiscal externalities have been a focus of numerous papers over the past 25 years. While increases in taxes on a mobile tax base in one jurisdiction will lead to a decrease in the tax base there, such increases in taxes will lead to an increase in the other jurisdiction's tax bases. The vertical tax externality arises when different levels of government simultaneously tax the same base. Vertical tax externalities act in both directions: federal taxes affect state revenues and state taxes affect federal revenues. Recently, the attention of researchers in the literature on vertical tax competition has been drawn to the analysis of fiscal externalities among different hierarchical layers of federations. Dahlby and Wilson (2003) [6] provide a model where a state government proposes a productivity-enhancing public input and both the state and the central government tax wages and profits to examine vertical fiscal externalities. Previous studies show that if consideration has been given to two levels of government imposing distortionary taxes on the same tax base, then a negative tax externality will arise.

In addition, the overlapping of tax bases gives rise to

${ }^{1}$ Chia and Phang (2001) [3] had analyses the use of motor vehicle taxes in Singapore as an environmental management instrument. de Mello (2008) [4] tests for horizontal tax competition in the value-added tax for a sample of Brazilian states in the period 1985-2001. 
the public sector version of a new problem. A number of studies have, for instance, focused on the tax policies of two levels of government, namely, state and federal, with overlapping tax bases. Hoyt (2001) [5] provides two cases, one of which assumes that the federal and state governments have identical tax bases. In this case, both governments tax both commodities. The other case assumes that the state government has a limited tax base and can only tax one commodity while the federal government still taxes both commodities. While Hoyt's paper examines the tax policy within a hierarchical system of government and departs from previous studies in several ways, it is assumed that all states are identical ${ }^{2}$. To fully understand the implications of independent tax policies under heterogeneous states, our paper seeks to relax this simplifying assumption.

Besley and Rosen (1998) [7] were the first researchers to test empirically for the presence of vertical tax externalities, examining the case of unit taxes on gasoline and tobacco. However, they did not take into account the price differences across states that arise because high cost areas pay less in real terms than low cost areas, since federal unit sales taxes on cigarettes and gasoline do not differ across states. Consequently, Esteller-Moré and Rizzo (2011) [8] applied US data from 1975-2006 to propose that vertical tax competition can be estimated by using a federal tax variable that is expressed in real terms and thus shows cross-sectional variation across states. In their study, they test the impact of state taxes on gasoline and cigarettes of increases in federal excise taxes on these items, and provide evidence that an increase in the federal tax does not affect state tax rates in either case.

The purpose of this article is to provide new insights into the federal tax policies of heterogeneous states. We propose a theoretical model to explain how the federal government decides its tax policy when faced with vertical externalities in heterogeneous states. Our results can be related to recent results and proved through the empirical study of Esteller-Moré and Rizzo (2011) [8]. The remainder of the paper is organized as follows. Section 2 consists of a brief model. In Section 3, we analyze the federal tax policy in the case of a unified government. In Section 4, we analyze the federal government's tax policy where each local government has a different tax base. Our conclusions are presented in Section 5.

\section{The Model}

The basic structure of the model is based on Hoyt

\footnotetext{
${ }^{2}$ Brülhart and Jametti (2006) [9] also derived a discriminating hypothesis to distinguish vertical and horizontal tax externalities based on measurable variables. Their paper found that vertical externalities dominate. Mandiès (2008) [10] found that some results related to whether equilibrium state taxes are likely to be too high or too low are much more complex when state-provided industrial public goods are considered.
}

(2001)'s [3] model. The federation we consider consists of two levels of government, a federal level and a state one, where each level of government has taxing and spending authority. In this case we focus on the overlap in the tax bases between the two levels of government. We assume that there is one input (labor) used in the production of the two consumption goods $x_{1}^{i}$ and $x_{2}^{i}$ in state $i$. We also assume that both of the goods are normal. In addition, we assume that the $n \geq 1$ states are heterogeneous in all relevant aspects. In each state $i$, there are two publicly-provided goods or services. One of the public goods is uniformly provided throughout the country at the level $G$ by the federal government. The other one is provided by the state to its residents, with $g^{i}$ being the level of service in state $i, i=1, \cdots, n$. The model is designed to keep the analysis simple. Thus, there is no horizontal fiscal externality among the state governments.

One unit of labor produces one unit of any of the private goods or one unit per resident of either of the services. Given these production requirements, as in Hoyt (2001) [7], pretax prices can be normalized to unity, or the price of a unit of labor. Let $\tau_{j f}^{i}$ and $\tau_{j s}^{i}$ denote the tax rates levied by the federal government $(f)$ and state government (s), respectively, on commodity $j, j=1$ and 2 in state $i$. Then the gross price of $x_{j}^{i}$ in state $i, q_{j}^{i}$, equals $1+\tau_{j f}^{i}+\tau_{j s}^{i}$ and $q^{i}$ denotes the vector of gross prices, $\left(q_{1}^{i}, q_{2}^{i}\right)$, in state $i$. The indirect utility function for the resident of state $i$ is given by $V^{i}\left(q_{1}^{i}, q_{2}^{i}, g^{i}, G\right)$.

\section{Federal Tax Policy in a Unified Government}

The federal government is assumed to maximize the social welfare function and tax the entire tax base. Since all states are heterogeneous, it seems realistic to assume that the tax and expenditure policy chosen only by the unified government will maximize the social welfare function which will be of the Bergson-Samuelson type. If the unified government can set its tax rates on both commodities to those of state $i$, and $\tau_{1 f}^{i}$ and $\tau_{2 f}^{i}$ also set a unique level of public goods for each state $i$, the problem of the unified government becomes

$$
\begin{aligned}
& \text { Maximize } W\left(V^{1}, V^{2}, \cdots, V^{n}\right) \\
& \text { s.t } \sum_{i=1}^{n}\left(\tau_{1}^{i} x_{1}^{i}+\tau_{2}^{i} x_{2}^{i}\right)=G+\sum_{i=1}^{n} g^{i}
\end{aligned}
$$

The first-order conditions for (1) with respect to the tax rates and the level of public goods in state $i$ are

$$
\frac{\partial L_{u}}{\partial g^{i}}=\frac{\partial W}{\partial V^{i}} \cdot \frac{\partial V^{i}}{\partial g^{i}}-\lambda=0
$$




$$
\begin{aligned}
& \frac{\partial L_{u}}{\partial \tau_{j}^{i}}=\frac{\partial W}{\partial V^{i}} \cdot \frac{\partial V^{i}}{\partial q_{j}^{i}}+\lambda\left[x_{j}^{i}+\sum_{k=1}^{2} \tau_{k}^{i} \frac{\partial x_{k}^{i}}{\partial q_{j}^{i}}\right]=0, \\
& j=1,2 ; i=1,2, \cdots, n .
\end{aligned}
$$

where $L_{u}$ denotes the maximum value function for the unified government.

From Roy's identity $\partial V^{i} / \partial q_{j}^{i}=-\alpha^{i} x_{j}^{i}$, where $\alpha^{i}$ is the marginal utility of income in state $i, \partial V^{i} / \partial I^{i}$. The Slutsky decomposition gives

$$
\frac{\partial x_{k}^{i}}{\partial q_{j}^{i}}=\frac{\partial h_{k}^{i}}{\partial q_{j}^{i}}-x_{j}^{i} \frac{\partial x_{k}^{i}}{\partial I^{i}}
$$

where $h_{k}^{i}(\cdot)$ is the compensated demand for commodity $k$ and the symmetry of the Slutsky matrix yields $\partial h_{k}^{i} / \partial q_{j}^{i}=\partial h_{j}^{i} / \partial q_{k}^{i}$, Then making these substitutions in (2b) gives

$$
\begin{aligned}
& \frac{\partial W}{\partial V^{i}}\left(-\alpha^{i} x_{j}^{i}\right)+\lambda\left[x_{j}^{i}+\sum_{k=1}^{2} \tau_{k}^{i}\left(\frac{\partial h_{j}^{i}}{\partial q_{k}^{i}}-x_{j}^{i} \frac{\partial x_{k}^{i}}{\partial I^{i}}\right)\right]=0, \\
& j=1,2 ; i=1,2, \cdots, n
\end{aligned}
$$

Rearranging terms enables us to express (3) as

$$
\frac{\beta^{i}}{\lambda} x_{j}^{i}=x_{j}^{i}\left(1-\sum_{k=1}^{2} \tau_{k}^{i} \frac{\partial x_{k}^{i}}{\partial I^{i}}\right)+\sum_{k=1}^{2} \tau_{k}^{i} \frac{\partial h_{j}^{i}}{\partial q_{k}^{i}}
$$

where $\beta^{i}$ denotes the marginal social utility of income in state $i$. Dividing (4) by $x_{j}^{i}$, letting $\eta_{j k}^{i}$ be the compensated price elasticity of demand for good $j$ with respect to the price of good $k$, and rearranging give

$$
\frac{\beta^{i}}{\lambda}-1+\sum_{k=1}^{2} \tau_{k}^{i} \frac{\partial x_{k}^{i}}{\partial I^{i}}=\tilde{\tau}_{1}^{i} \eta_{j 1}^{i}+\tilde{\tau}_{2}^{i} \eta_{j 2}^{i}
$$

Let us assume

$$
\theta_{j}^{i}=\frac{\beta^{i}}{\lambda}-1+\sum_{k=1}^{2} \tau_{k}^{i} \frac{\partial x_{k}^{i}}{\partial I^{i}}=\tilde{\tau}_{1}^{i} \eta_{j 1}^{i}+\tilde{\tau}_{2}^{i} \eta_{j 2}^{i}
$$

\subsection{Tax on Commodities in the Same State}

In the following case, the federal government can tax both commodities, $x_{1}^{i}$ and $x_{2}^{i}$, but the states cannot tax one of them. By denoting $\theta^{*}$ as representing the effect of distortion or the excess burden on marginal tax revenue, we can then obtain

$$
\tilde{\tau}_{1}^{i}\left(\eta_{11}^{i}-\eta_{21}^{i}\right)=\tilde{\tau}_{2}^{i}\left(\eta_{22}^{i}-\eta_{12}^{i}\right)
$$

where $\theta_{1}^{i}=\theta_{2}^{i}=\theta^{*}$. The term $\eta_{j k}^{i}$ is the compensated price elasticity of demand for good $j$ with respect to the price of good $k$ in state $i$. Given $\eta_{21}^{i}=\eta_{12}^{i}$, we can obtain the inverse elasticity rule if $\eta_{11}^{i}>\eta_{22}^{i}$, then $\tilde{\tau}_{1}^{i}<\tilde{\tau}_{2}^{i}$.
Using (7), we can solve for the tax rates as a function of $\theta^{*}$ with

$$
\tilde{\tau}_{j}^{i *}=\left(\frac{\eta_{k k}^{i}-\eta_{j k}^{i}}{\eta_{22}^{i} \eta_{11}^{i}-\eta_{21}^{i} \eta_{12}^{i}}\right) \theta^{*}, \text { for } j, k=1,2 ; j \neq k .
$$

In the case of a unified government, the tax policy will depend on the magnitude of the compensated price elasticity of demand.

\subsection{Taxes on Commodities in Different States}

The unified government will choose its taxes given that the commodity is to be sold in different states. In this heterogeneous state case, the government should maximize the marginal social utility of public goods in all states as being equal. We can use (5) to obtain

$$
\begin{gathered}
\frac{\beta^{i}}{\lambda}=1-\sum_{k=1}^{2} \tau_{k}^{i} \frac{\partial x_{k}^{i}}{\partial I^{i}}+\tilde{\tau}_{1}^{i} \eta_{11}^{i}+\tilde{\tau}_{2}^{i} \eta_{12}^{i}=1+\tilde{\tau}_{1}^{i} \xi_{11}^{i}+\tilde{\tau}_{2}^{i} s^{i} \xi_{21}^{i} \\
\frac{\beta^{n}}{\lambda}=1-\sum_{k=1}^{2} \tau_{k}^{n} \frac{\partial x_{k}^{n}}{\partial I^{i}}+\tilde{\tau}_{1}^{n} \eta_{11}^{n}+\tilde{\tau}_{2}^{n} \eta_{12}^{n}=1+\tilde{\tau}_{1}^{n} \xi_{11}^{n}+\tilde{\tau}_{2}^{n} s^{n} \xi_{21}^{n}
\end{gathered}
$$

where $\xi_{j k}^{i}$ denotes the cross elasticity and $s^{i}$ and $s^{n}$ are the shares of expenditure on commodities in state $i$ and $n$, as follows:

$$
s^{i}=\frac{q_{2}^{i} x_{2}^{i}}{q_{1}^{i} x_{1}^{i}}, s^{n}=\frac{q_{2}^{n} x_{2}^{n}}{q_{1}^{n} x_{1}^{n}}
$$

Finally, from (9) and (10), the marginal social utility of public goods may be expressed as

$$
\lambda=\frac{\beta^{i}}{1+\tilde{\tau}_{1}^{i} \xi_{11}^{i}+\tilde{\tau}_{2}^{i} s^{i} \xi_{21}^{i}}=\frac{\beta^{n}}{1+\tilde{\tau}_{1}^{n} \xi_{11}^{n}+\tilde{\tau}_{2}^{n} s^{n} \xi_{21}^{n}}
$$

Assuming that the unified government treats the residents in different states alike, we will have

$$
\frac{\partial W}{\partial V^{i}}=\frac{\partial W}{\partial V^{n}}, i \neq n
$$

It is apparent that $\beta^{i}$ will be affected by $\alpha^{i}$ given $\beta^{i}=\left(\partial W / \partial V^{i}\right) \alpha^{i}$. Given this and the other implications above, we have:

Proposition 1. In the unified government case, supposing the marginal utilities of income are the same, the tax policy in state i not only considers the price elasticity and cross elasticity of each state but also the shares of expenditure on commodity $x_{1}$ and $x_{2}$ in different states. When the cross elasticity is zero, the tax rates on the same commodity sold in different states and the price elasticity should be inversely related.

Proposition 2. If the cross elasticity of a commodity is zero, the higher the marginal utility of income in state $i$, the lower the tax rate that should be set by the unified government in that state. 


\section{Tax Policy in Federal and State Governments}

In this section, there are governments at different levels, namely, federal and state governments. Each local government has a different tax base from that of the federal government, at least nominally. However, it is not easy to differentiate among the tax bases for these two levels of government and, as a result, the tax bases of the federal and state governments are overlapping. In other words, the tax policies of the federal and state governments will affect the decisions of the private sector and moreover the tax bases will overlap. In such a case, a vertical externality may result. Our analysis assumes that residents cannot purchase commodities among the different states. Thus, there is no tax competition among the state governments, and the horizontal externality may therefore be ignored.

\subsection{Identical Tax Bases}

Assume that the tax and expenditure policy chosen by the state government will maximize aggregated utility. If the state government can set tax rates on both commodities, $x_{1}$ and $x_{2}$, the problem of the state $i$ government is

$$
\begin{aligned}
& \operatorname{Maximize} V^{i}\left(q_{1}^{i}, q_{2}^{i}, g^{i}, G\right) \\
& \text { s.t } \tau_{1 s}^{i} x_{1}^{i}+\tau_{2 s}^{i} x_{2}^{i}=g^{i} \\
& \sum_{i=1}^{n}\left(\tau_{1 f}^{i} x_{1}^{i}+\tau_{2 f}^{i} x_{2}^{i}\right)=G
\end{aligned}
$$

Maximizing utility with respect to tax rates for state $i$, $\tau^{i}$, and using the rent function (11) and the government budget constraints, we can express the indirect utility function for state $i$ as

$$
\begin{aligned}
L= & V^{i}\left(q_{1}^{i}, q_{2}^{i}, g^{i}, G\right)+\lambda^{i}\left(\tau_{1 s}^{i} x_{1}^{i}+\tau_{2 s}^{i} x_{2}^{i}-g^{i}\right) \\
& +\gamma\left[\sum_{i=1}^{n}\left(\tau_{1 f}^{i} x_{1}^{i}+\tau_{2 f}^{i} x_{2}^{i}\right)-G\right]
\end{aligned}
$$

Let $M R S_{f s}^{i}=\gamma / \lambda^{i}=\left(\partial V^{i} / \partial G\right) /\left(\partial V^{i} / \partial g^{i}\right)$ denote the marginal rate of substitution between the state and federal public services. Rearranging the terms enables us to express as

$$
\begin{aligned}
& \frac{\alpha^{i}}{\lambda^{i}}-1+\sum_{k=1}^{2} \frac{\partial x_{k}^{i}}{\partial I^{i}}\left(\tau_{k s}^{i}+M R S_{f s}^{i} \tau_{k f}^{i}\right)=\sum_{k=1}^{2} \eta_{j k}^{i}\left(\tilde{\tau}_{k s}^{i}+M R S_{f s}^{i} \tilde{\tau}_{k f}^{i}\right), \\
& j=1,2
\end{aligned}
$$

Given

$$
\begin{aligned}
& \theta_{1 s}^{i}=\eta_{11}^{i}\left(\tilde{\tau}_{1 s}^{i}+M R S_{f s}^{i} \tilde{\tau}_{1 f}^{i}\right)+\eta_{12}^{i}\left(\tilde{\tau}_{2 s}^{i}+M R S_{f s}^{i} \tau_{2 f}^{i}\right), \\
& \theta_{2 s}^{i}=\eta_{21}^{i}\left(\tilde{\tau}_{1 s}^{i}+M R S_{f s}^{i} \tilde{\tau}_{1 f}^{i}\right)+\eta_{22}^{i}\left(\tilde{\tau}_{2 s}^{i}+M R S_{f s}^{i} \tau_{2 f}^{i}\right)
\end{aligned}
$$

If we impose symmetry on the compensated price elasticity of demand for good $j$ with respect to the price of good $k$ and the state government is assumed to maximize social welfare, then the excess burdens from taxing each commodity should be equal to each other. Taking $\theta_{1 s}^{i}=\theta_{2 s}^{i}=\theta_{s}^{*}$ as given in each state, we obtain

$$
\left(\eta_{11}^{i}-\eta_{21}^{i}\right)\left(\tilde{\tau}_{1 s}^{i}+M R S_{f s}^{i} \tilde{\tau}_{1 f}^{i}\right)=\left(\eta_{22}^{i}-\eta_{12}^{i}\right)\left(\tilde{\tau}_{2 s}^{i}+M R S_{f s}^{i} \tilde{\tau}_{2 f}^{i}\right)
$$

Expression (14) allows us to recognize that if $\eta_{11}^{i}>\eta_{22}^{i}$, then the combined state and federal tax on commodity $x_{1}$ is less than it is on commodity $x_{2}$ for the state government. In addition, by taking (13) into consideration, the state optimal tax rates can be solved as

$$
\tilde{\tau}_{1 s}^{i *}=-M R S_{f s}^{i} \tilde{\tau}_{1 f}^{i}+\left(\frac{\eta_{22}^{i}-\eta_{12}^{i}}{\eta_{22}^{i} \eta_{11}^{i}-\eta_{21}^{i} 1_{12}^{i}}\right) \theta_{s}^{*}
$$

and

$$
\tilde{\tau}_{2 s}^{i *}=-M R S_{{ }_{s}}^{i} \tilde{\tau}_{2 f}^{i}+\left(\frac{\eta_{11}^{i}-\eta_{21}^{i}}{\eta_{22}^{i} \eta_{11}^{i}-\eta_{21}^{i} \eta_{12}^{i}}\right) \theta_{s}^{*}
$$

In the case of identical tax bases, i.e., where the bases are overtaxed, the effect of the federal tax on the state tax as can be seen from (15a) and (15b) depends on $M R S_{f s}^{i}$. In other words, if the government of state $i$ does not take into account the possibility that public goods provided by the federal and state governments, $G$ and $g^{i}$, are substitutes, the state tax rates for $x_{1}$ and $x_{2}$ may only be set by $\eta_{11}^{i}$ and $\eta_{22}^{i}$.

In addition, where there are different hierarchical government levels, the federal government is assumed to maximize social welfare and only provides country-level public goods which are financed from taxes levied on $x_{1}$ and $x_{2}$. The federal government's problem is

$$
\begin{aligned}
& \operatorname{Max} W\left(V^{1}, V^{2}, \cdots, V^{n}\right) \\
& \text { s.t } \sum_{i=1}^{n}\left(\tau_{1 f}^{i} x_{1}^{i}+\tau_{2 f}^{i} x_{2}^{i}\right)=G
\end{aligned}
$$

By making the same substitutions and process, we can have

$$
\beta^{i} x_{j}^{i}-\frac{\partial W}{\partial V^{i}} \frac{\partial V^{i}}{\partial g^{i}} \sum_{k=1}^{2} \tau_{k s}^{i} \frac{\partial x_{k}^{i}}{\partial q_{j}^{i}}=\phi\left[x_{j}^{i}+\sum_{k=1}^{2} \tau_{k f}^{i} \frac{\partial x_{k}^{i}}{\partial q_{j f}^{i}}\right]
$$

Finally, dividing by $\phi$ gives

$$
\begin{aligned}
& \frac{\beta^{i}}{\phi}-1+S M R S_{s f}^{i} \sum_{k=1}^{2} \tau_{k s}^{i} \frac{\partial x_{k}^{i}}{\partial I^{i}}+\sum_{k=1}^{2} \tau_{k f}^{i} \frac{\partial x_{k}^{i}}{\partial I^{i}} \\
= & S M R S_{s f}^{i} \sum_{k=1}^{2} \tilde{\tau}_{k s}^{i} \eta_{j k}^{i}+\sum_{k=1}^{2} \tilde{\tau}_{k f}^{i} \eta_{j k}^{i}
\end{aligned}
$$

where 


$$
S M R S_{s f}^{i}=\frac{\frac{\partial W}{\partial V^{i}} \cdot \frac{\partial V^{i}}{\partial g^{i}}}{\sum_{i=1}^{n} \frac{\partial W}{\partial V^{i}} \cdot \frac{\partial V^{i}}{\partial G}}
$$

which implies the marginal rate of substitution between the public goods of state $i$ and the federal government ${ }^{3}$.

In this heterogeneous state case, the social-welfare maximizing federal government should consider both the economic efficiency and income distribution. Where the federal government taxes two commodities, $x_{1}$ and $x_{2}$, in state $i$, the marginal excess burden of the tax on good $i$ must be equal to that on good $j$.

We denote $\theta_{1 f}^{i}$ as representing the effect of the excess burden to marginal tax revenue on good 1 by the federal government in state $i$. Thus, we have

$$
\begin{aligned}
& \theta_{1 f}^{i} \\
= & \frac{\beta^{i}}{\phi}-1+S M R S_{s f}^{i} \sum_{k=1}^{2} \tau_{k s}^{i} \frac{\partial x_{k}^{i}}{\partial I^{i}}+\sum_{k=1}^{2} \tau_{k f}^{i} \frac{\partial x_{k}^{i}}{\partial I^{i}} \\
= & \eta_{11}^{i}\left(\tilde{\tau}_{1 f}^{i}+S M R S_{s f}^{i} \tilde{\tau}_{1 s}^{i}\right)+\eta_{12}^{i}\left(\tilde{\tau}_{2 f}^{i}+S M R S_{s f}^{i} \tilde{\tau}_{2 s}^{i}\right)
\end{aligned}
$$

Hence,

$$
\theta_{2 f}^{i}=\eta_{21}^{i}\left(\tilde{\tau}_{1 f}^{i}+S M R S_{s f}^{i} \tilde{\tau}_{1 s}^{i}\right)+\eta_{22}^{i}\left(\tilde{\tau}_{2 f}^{i}+S M R S_{s f}^{i} \tilde{\tau}_{2 s}^{i}\right)
$$

Using (19a) and (19b), we can obtain $\theta_{1 f}^{i}=\theta_{2 f}^{i}=\theta_{f}^{*}$. Then this gives

$$
\begin{aligned}
& \left(\eta_{11}^{i}-\eta_{21}^{i}\right)\left(\tilde{\tau}_{1 f}^{i}+S M R S_{s f}^{i} \tau_{1 s}^{i}\right) \\
= & \left(\eta_{22}^{i}-\eta_{12}^{i}\right)\left(\tilde{\tau}_{2 f}^{i}+S M R S_{s f}^{i} \tilde{\tau}_{2 s}^{i}\right)
\end{aligned}
$$

As (20) suggests, if the compensated price elasticity of demand for $x_{1}$ with respect to its price in state $i$ is greater than it is for $x_{2}\left(\eta_{11}^{i}>\eta_{22}^{i}\right)$, then the optimal set of tax rates for commodity $x_{1}$ is lower than it is for commodity $x_{2}$ for the federal government. In addition, we also can use (19a) and (19b) to solve for the optimal tax rates for the federal government as follows:

$$
\begin{gathered}
\tilde{\tau}_{1 f}^{i *}=-S M R S_{s f}^{i} \tilde{\tau}_{1 s}^{i}+\left(\frac{\eta_{22}^{i}-\eta_{12}^{i}}{\eta_{22}^{i} \eta_{11}^{i}-\eta_{21}^{i} \eta_{12}^{i}}\right) \theta_{f}^{*} \\
\tilde{\tau}_{2 f}^{i *}=-S M R S_{s f}^{i} \tilde{\tau}_{2 s}^{i}+\left(\frac{\eta_{11}^{i}-\eta_{21}^{i}}{\eta_{22}^{i} \eta_{11}^{i}-\eta_{21}^{i} \eta_{12}^{i}}\right) \theta_{f}^{*}
\end{gathered}
$$

This, together with (21a) and (21b), which is based on the case where the states are overtaxed, indicates that the effect of state tax rates on federal government policy depends on $S M R S_{s f}^{i}$. The federal government should thus impose a lower tax on the goods with a higher compensated price elasticity of demand when the difference

${ }^{3}$ When the weighting of each state is the same within the federal government and publicly-provided goods are uniformly provided throughout the country at the same level $G, S M R S_{s f}^{i}=1 / n M R S_{f s}^{i}$. between the marginal social utility of public goods provided by state $i$ and the federal government is close to zero. (i.e., $S M R S_{\text {sf }}^{i} \rightarrow 0$ )

We now consider the case in which the federal government can tax the commodities which are sold in different states. In this case, the federal government should adjust the marginal social utilities of the public goods provided by the federal government so that they are equal in each state. When federal and state tax policies have identical tax bases, the tax policy of the federal government will be based on having the same tax rates for each good in the different states. From Equation (18) and by considering commodity $x_{1}(j=1)$, we could determine the marginal social utility of public goods as

$$
\phi=\frac{\beta^{n}}{1+\xi_{11}^{n}\left(\tilde{\tau}_{1 f}^{n}+\tilde{\tau}_{1 s}^{n} S M R S_{s f}^{n}\right)+\xi_{21}^{n} s^{n}\left(\tilde{\tau}_{2 f}^{n}+\tilde{\tau}_{2 s}^{n} S M R S_{s f}^{n}\right)}
$$

Based on (22), in the case where tax bases are identical, the tax rates on commodities, $x_{1}$ and $x_{2}$, in different states will depend on the price elasticity of demand, cross elasticity of demand, relative expenditures on commodities in each state and the social marginal rate of substitution between federal and state services or public goods, given the identical weights attached to each state government by the federal government, i.e.,

$$
\frac{\partial W}{\partial V^{i}}=\frac{\partial W}{\partial V^{n}}, i \neq n \text {. }
$$

This and other implications lead to Propositions 3 and 4:

Proposition 3. 1) If the marginal utility of income in each state is identical and the cross elasticity of demand is zero, the aggregate tax rates of the federal and state governments should be lower when the price elasticity of demand for state $i$ is greater; 2) The impact of the state government's tax policy on the federal government's tax policy depends on $\mathrm{SMRS}_{\text {sf }}$ The federal government's tax policy could be set only by considering the price elasticity of demand in each state ${ }^{4}$.

Proposition 4. In the case of identical tax bases and with cross elasticities of demand among commodities being equal to zero, the higher the marginal utility of income in state $i$, the lower will be the aggregate tax rates for the federal and state governments' tax policy in state $i$.

\subsection{Partially Overlapping Tax Bases for the Federal and State Governments}

This section considers the case in which the state government only can tax commodity $x_{1}$ but the federal government can tax the entire base, i.e., $x_{1}$ and $x_{2}$.

${ }^{4}$ This results can be proved through the empirical study of Esteller-Moré and Rizzo (2011) [8]. 
The federal government finances federal public goods and services from the entire base, while the state government only finances the local public goods and services by taxing commodity $x_{1}$. Then the government of state $i$ chooses its tax rates to solve

$$
\begin{gathered}
\text { Maximize } V^{i}\left(q_{1}^{i}, g^{i}, G\right) \\
\text { s.t } \tau_{1 s}^{i} x_{1}^{i}=g^{i} \\
\sum_{i=1}^{n}\left(\tau_{1 f}^{i} x_{1}^{i}+\tau_{2 f}^{i} x_{2}^{i}\right)=G
\end{gathered}
$$

The first-order conditions for (31)-(31b) with respect to the tax rates are

$$
\frac{\partial L}{\partial \tau_{1 s}^{i}}=\frac{\partial V^{i}}{\partial q_{1}^{i}}+\lambda\left(x_{1}^{i}+\tau_{1 s}^{i} \frac{\partial x_{k}^{i}}{\partial q_{j}^{i}}\right)+\gamma \sum_{k=1}^{2} \tau_{k f}^{i} \frac{\partial x_{k}^{i}}{\partial q_{j}^{i}}=0
$$

As should be apparent, given the identical structure of (24) in relation to the social-welfare maximizing rule, (23), solving (24) for the optimal tax rates of state government $i$ gives

$$
\tau_{1 s}^{i *}=\frac{\theta_{1 s}^{i}}{\eta_{11}^{i}}-M R S_{f s}^{i}\left(\frac{\eta_{12}^{i}}{\eta_{11}^{i}} \tilde{\tau}_{2 f}^{i}+\tilde{\tau}_{1 f}^{i}\right)
$$

where

$$
\begin{aligned}
\theta_{1 s}^{i} & =\frac{\alpha^{i}}{\lambda^{i}}-1+\frac{\partial x_{1}^{i}}{\partial I}\left(\tau_{1 s}^{i}+M R S_{f s}^{i} \tau_{1 f}^{i}\right)+\frac{\partial x_{2}^{i}}{\partial I} M R S_{f s}^{i} \tau_{2 f}^{i} \\
& =M R S_{f s}^{i}\left(\eta_{12}^{i} \tilde{\tau}_{2 f}^{i}+\eta_{11}^{i} \tau_{1 f}^{i}\right)+\eta_{11}^{i} \tilde{\tau}_{1 s}^{i}
\end{aligned}
$$

Given (25), the effect of the federal tax policy on the state government completely depends on $M R S_{f s}^{i}$ and the compensated price elasticity of demand. If $M R S_{f s}^{i}=0$, then the expression indicates that the federal government's tax policy will not have an influence on the tax policy of the state government. Since the state government only imposes a tax on commodity $x_{1}$, it will tax the commodity with lower compensated price elasticity of demand to minimize the welfare cost of taxation. As $\eta_{12}^{i}=0$, the tax policy of the state government will only be affected by $\tilde{\tau}_{1 f}^{i}$. Thus, the federal government is assumed to maximize

$$
L=W\left(V^{1}, V^{2}, \cdots, V^{n}\right)+\phi\left[\sum_{i=1}^{n}\left(\tau_{1 f}^{i} x_{1}^{i}+\tau_{2 f}^{i} x_{2}^{i}\right)-G\right]
$$

If the federal government taxes two commodities, $x_{1}$ and $x_{2}$, in state $i$, we can obtain $\theta_{1 f}^{i}=\theta_{2 f}^{i}=\theta_{f}^{*}$. Based on $\theta_{1 f}^{i}=\theta_{2 f}^{i}=\theta_{f}^{*}$, we obtain the optimal tax rate set by the federal government for the two commodities in state $i$ :

$$
\tilde{\tau}_{1 f}^{i *}=-S M R S_{s f}^{i} \tilde{\tau}_{1 s}^{i}+\left(\frac{\eta_{22}^{i}-\eta_{12}^{i}}{\eta_{22}^{i} \eta_{11}^{i}-\eta_{21}^{i} \eta_{12}^{i}}\right) \theta_{f}^{*}
$$

$$
\tilde{\tau}_{2 f}^{i *}=\left(\frac{\eta_{11}^{i}-\eta_{21}^{i}}{\eta_{22}^{i} \eta_{11}^{i}-\eta_{21}^{i} \eta_{12}^{i}}\right) \theta_{f}^{*}
$$

Due to the tax bases of the federal and state governments being partially overlapping and the state government only being able to tax commodity $x_{1}$, the optimal tax rules for the two commodities in state $i$ are determined by the federal government. Hence, if $\eta_{11}^{i}>\eta_{22}^{i}$, the aggregate tax rate for $x_{1}$ among the states imposed by the federal government should be lower than that for $x_{2}$.

In general, then, when commodity $x_{1}$ is sold in different states, Equation (24) turns out to be

$$
\frac{\beta^{i}}{\phi}=\xi_{11}^{i}\left(\tilde{\tau}_{1 f}^{i}+S M R S_{s f}^{i} \tilde{\tau}_{1 s}^{i}\right)+s^{i} \xi_{21}^{i} \tilde{\tau}_{2 f}^{i}+1
$$

and

$$
\frac{\beta^{n}}{\phi}=\xi_{j 1}^{n}\left(\tilde{\tau}_{1 f}^{n}+S M R S_{s f}^{n} \tilde{\tau}_{1 s}^{n}\right)+s^{n} \xi_{21}^{n} \tilde{\tau}_{2 f}^{n}+1
$$

Using (27a) and (27b), we can rewrite this expression as

$$
\phi=\frac{\beta^{n}}{1+\xi_{11}^{n}\left(\tilde{\tau}_{1 f}^{n}+S M R S_{s f}^{n} \tilde{\tau}_{1 s}^{n}\right)+\xi_{21}^{n} s^{n} \tilde{\tau}_{2 f}^{n}}
$$

Supposing that the cross elasticity of demand is zero, then (28) can be rewritten as

$$
\phi=\frac{\beta^{i}}{1+\xi_{11}^{i}\left(\tilde{\tau}_{1 f}^{i}+S M R S_{s f}^{i} \tilde{\tau}_{1 s}^{i}\right)}=\frac{\beta^{n}}{1+\xi_{11}^{n}\left(\tilde{\tau}_{1 f}^{n}+S M R S_{s f}^{n} \tilde{\tau}_{1 s}^{n}\right)}
$$

What is also interesting is that regardless of whether the tax base is identical or not, the tax policy implemented by the federal government is based on the same rules.

Turning now to commodity $x_{2}$, when the cross elasticity of demand between $x_{1}$ and $x_{2}$ is equal to zero, we can then obtain

$$
\phi=\frac{\beta^{i}}{1+\xi_{22}^{i} \tilde{\tau}_{2 f}^{i}}=\frac{\beta^{n}}{1+\xi_{22}^{n} \tilde{\tau}_{2 f}^{n}}
$$

From the previous discussion, the marginal social utilities of income for different states are in equilibrium in terms of the marginal utilities of income in states $i$ and $n$ being equal. This leads to $\xi_{22}^{i} \tilde{\tau}_{2 f}^{i}=\xi_{22}^{n} \tilde{\tau}_{2 f}^{n}$. Conversely, if the marginal utility of income in state $i$ is greater than it is in state $n$, then this gives

$\xi_{22}^{i} \tilde{\tau}_{2 f}^{i}>\xi_{22}^{n} \tilde{\tau}_{2 f}^{n}$. Hence, $\tilde{\tau}_{2 f}^{i}<\frac{\left|\xi_{22}^{n}\right|}{\left|\xi_{22}^{i}\right|} \tilde{\tau}_{2 f}^{n}$. Since the federal tax on commodity $x_{2}$ is not taxed by the states, the tax rates applying to $x_{2}$ will be determined by the federal government based on the inverse elasticity rule since the 
Table 1. Optimal tax rates of state $i$ and the federal government.

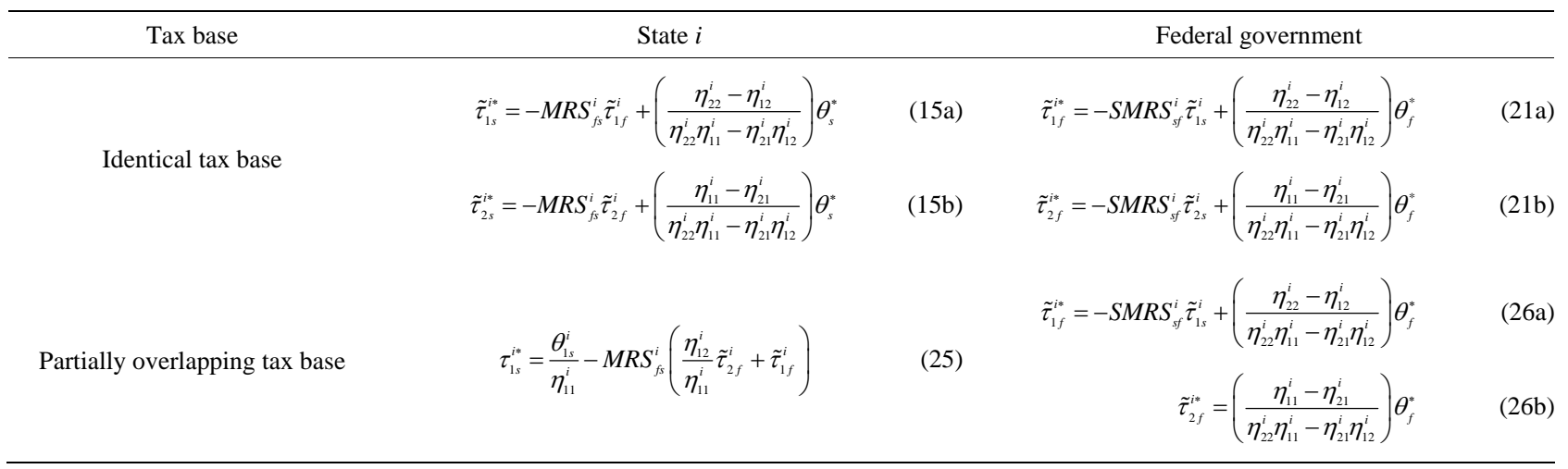

cross elasticity of demand is zero. This result is in stark contrast to the policies in the case where the tax bases of the state and federal governments are completely overlapping. When the cross elasticity of demand is zero, the tax rate for commodity $x_{1}$ depends not only on the price elasticity of demand, but on the tax rates in state $i$ and the social marginal rate of substitution between the state and federal governments' services.

\section{Conclusion}

In this paper, we propose a theoretical model to explain how the federal government decides its tax policy when faced with vertical externalities in heterogeneous states. The results obtained in this paper may be summarized as follows: 1) If the unified government maximizes social welfare, the tax rate selected for the commodity should be inversely related to the compensated price elasticity of demand for the goods on which the tax is levied within a state. When the cross price elasticity is zero, the state with low incomes should have a lower commodity tax rate; 2) In a multi-level government, when the state and federal tax bases are identical, the combined state and federal taxes should be inversely related to the compensated price elasticities of demand for the goods on which they are levied within a state. The federal tax rate must take into consideration the rate of social marginal substitution of the state public goods and federal public goods when the federal government decides the tax rates for identical commodities in different states. Table 1 summarizes the optimal tax rates for state $i$ and the federal government for different tax bases.

\section{REFERENCES}

[1] B. Dahlby, "Fiscal Externalities and the Design of Inter- government Grants,” International Tax and Public Finance, Vol. 3, No. 3, 1996, pp. 397-412. doi:10.1007/BF00418952

[2] M. Keen, "Vertical Tax Externalities in the Theory of Fiscal Federalism,” IMF Staff Papers, Vol. 45, No. 3, 1998, pp. 454-485. doi:10.2307/3867412

[3] N. C. Chia and S. Y. Phang, "Motor Vehicle Taxes as an Environmental Management Instrument: The Case of Singapore,” Environmental Economics and Policy Studies, Vol. 4, No. 2, 2001, pp. 67-93.

[4] L. de Mello, “The Brazilian 'Tax War': The Case of ValueAdded Tax Competition among the States," Public Finance Review, Vol. 36, No. 2, 2008, pp. 169-193. doi:10.1177/1091142107299252

[5] W. H. Hoyt, "Tax Policy Coordination, Vertical Externalities and Optimal Taxation in a System of Hierarchical Government," Journal of Urban Economics, Vol. 50, No. 3, 2001, pp. 491-516. doi:10.1006/juec.2001.2231

[6] B. Dahlby and L. S. Wilson, "Vertical Fiscal Externalities in a Federation,” Journal of Public Economics, Vol. 87, No. 5-6, 2003, pp. 917-930. doi:10.1016/S0047-2727(01)00137-2

[7] T. J. Besley and H. S. Rosen, "Vertical Externalities in a Tax Setting: Evidence from Gasoline and Cigarettes," Journal of Public Economics, Vol. 70, No. 3, 1998, pp. 383-398. doi:10.1016/S0047-2727(98)00041-3

[8] A. Esteller-Moré and L. Rizzo, “(Uncontrolled) Aggregate Shocks or Vertical Tax Interdependence? Evidence from Gasoline and Cigarettes,” National Tax Journal, Vol. 64, 2011, pp. 353-380.

[9] M. Brülhart and M. Jametti, "Vertical versus Horizontal Tax Externalities: An Empirical Test,” Journal of Public Economics, Vol. 90, No. 10-11, 2006, pp. 2027-2062. doi:10.1016/j.jpubeco.2006.04.004

[10] T. Madiès, "Do Vertical Tax Externalities Lead to Tax Rates Being Too High? A Note,” Annals of Regional Science, Vol. 42, No. 1, 2008, pp. 225-233. doi:10.1007/s00168-007-0135-5 